\title{
Elaboração de uma sistemática de seleção de pregoeiros por competências no Instituto Federal de Santa Catarina Campus São José
}

\author{
Kelly Cristina Benetti Tonani Tosta \\ Doutora em Engenharia e Gestão do Conhecimento. Universidade Federal da Fronteira Sul (UFFS) Brasil. \\ kellytosta@uffs.edu.br \\ Roberto Paulo Vieira Pós-graduado em Gestão Pública. Instituo Federal de Educação, Ciência e Tecnologia de Santa Catarina (IFSC) \\ Brasil.rpvieira@ifsc.edu.br
}

\begin{abstract}
RESUMO
O processo de compras no serviço público apresenta particularidades impostas pela legislação vigente. O pregão tem sido a forma mais amplamente utilizada na aquisição de bens pelas instituições federais de ensino e exige pessoal capacitado para sua operação. Deste modo, o objetivo desta pesquisa consiste na elaboração de uma sistemática de seleção de pregoeiros por competências no (IFSC), campus São José. De acordo com a sua natureza, a pesquisa é classificada como aplicada, qualitativa e descritiva e quanto aos meios como pesquisa documental, de campo e participante, a partir de estudo de caso. Para a coleta de dados foram utilizadas a entrevista semiestruturada e a observação participante. O método análise de conteúdo foi utilizado para análise dos dados. A identificação das atribuições do pregoeiro segundo a legislação, das atividades realizadas além das atribuições, dos indicadores de competências traduzidos em conhecimentos, habilidades e atitudes ( $\mathrm{CHA}$ ), propiciou agrupar as competências necessárias para a função. A formação mais adequada, os cursos que deve possuir o pregoeiro, as dificuldades e facilidades encontradas na função foram obtidas. A inexistência de qualquer processo, procedimento ou qualquer critério para seleção foi constatada. Outro resultado relevante foi a consolidação da matriz de competências para a função, a partir das informações obtidas junto aos gestores ligados diretamente aos pregoeiros, e com os próprios pregoeiros. Como último resultado, gestores e pregoeiros citaram a definição de critérios e procedimentos para a designação do servidor, contribuindo para o aprimoramento do processo seletivo. Na conclusão do estudo, uma proposta de sistemática de seleção de pregoeiros por competências é apresentada ao campus São José (IFSC).
\end{abstract}

Palavras-chave: Competências. Pregoeiro. Seleção.

\section{Elaboration of a system for selection of auctioneers based on competences at the Instituto Federal de Santa Catarina Campus São José}

\begin{abstract}
The procurement process in the Public Service presents peculiarities imposed by the current legislation. The trading floor has been the most widely used way of acquiring assets by federal educational institutions and requires trained personnel for its operation. In this way, the objective of this research is to elaborate a system for the selection of auctioneers based on competences for IFSC, Campus São José. According to its nature, the research is classified as applied, qualitative and descriptive and as to the means, it is a documentary research, field and participant, supported by a case study. For data collection, the semi-structured interview and participant observation were used. The content analysis method was used for data analysis. The identification of the duties of auctioneers according to the legislation, the activities carried out beyond their attributions, the indicators of competences translated into knowledge, skills and attitudes (CHA), allowed to group the skills necessary for the function. The most adequate training, the courses auctioneers must have, the difficulties faced in the function were obtained. The absence of any process, procedure or any criterion for selection was verified. Another relevant result was the consolidation of the competence matrix for the function, based on the information obtained from the managers working directly with auctioneers, and with the auctioneers themselves. As a last result, managers and auctioneers cited the definition of criteria and procedures for the designation of the server, thus contributing to the improvement of the selection process. In the the conclusion of the study, a proposal for a system for the selection of auctioneers based on competences is presented to IFSC, Campus São José.
\end{abstract}

Keywords: Competences. Auctioneer. Selection. 


\title{
1 INTRODUÇÃO
}

Para adquirir um determinado bem ou contratar um serviço qualquer, ou até mesmo realizar uma obra de engenharia, as Instituições Federais de ensino superior - sejam elas as Universidades Federais ou os Institutos Federais - como os demais órgãos públicos, precisam seguir um rol de procedimentos previstos em lei, e que no direito administrativo recebe a denominação de licitação.

A principal lei que institui normas para licitação e contratos da administração pública, Lei n 8.666, de 21 de junho de 1993 (BRASIL, 1993, art. 30), traz a seguinte definição:

\begin{abstract}
A licitação destina-se a garantir a observância do princípio constitucional da isonomia, a seleção da proposta mais vantajosa para a administração e a promoção do desenvolvimento nacional sustentável e será processada e julgada em estrita conformidade com os princípios básicos da legalidade, da impessoalidade, da moralidade, da igualdade, da publicidade, da probidade administrativa, da vinculação ao instrumento convocatório, do julgamento objetivo e dos que lhes são correlatos.
\end{abstract}

Na lição de Meirelles (2002, p. 25) licitação é conceituada como:

[...] É o meio técnico-legal de verificação das melhores condições para a execução de obras e serviços, compra de materiais e alienação de bens públicos. Realiza-se através de uma sucessão ordenada de atos vinculantes para a administração e para os licitantes, sem a observância dos quais é nulo o procedimento licitatório, e o contrato subsequente.

Algumas modalidades licitatórias foram estabelecidas pela legislação pertinente. A Lei no 8.666/93 (BRASIL, 1993, art. $2^{\circ}$ ) relaciona e define cinco modalidades: concorrência, tomada de preços, convite, concurso e leilão.

Mais tarde, por meio da Medida Provisória n 2.026, de 4 de maio de 2000 (BRASIL, 2000a), a sexta modalidade licitatória denominada pregão foi instituída, e após sofrer sucessivas reedições, perdeu o seu efeito com o advento da Lei no 10.520, de 17 de junho de 2002 (BRASIL, 2002).

A citada medida provisória (BRASIL, 2000a, art. 2), apresenta a seguinte definição:

Pregão é a modalidade de licitação para aquisição de bens e serviços comuns, promovida exclusivamente no âmbito da União, qualquer que seja o valor estimado da contratação, em que a disputa pelo fornecimento é feita por meio de propostas e lances em sessão pública.

Ainda sobre a definição dessa nova modalidade, segundo Santana (2006, p. 26), o pregão é assim conceituado: “[...] procedimento administrativo ou instrumental através do qual a Administração Pública seleciona a oferta mais vantajosa, respeitados os princípios da legalidade, economicidade, isonomia dentre outros".

Para coordenar os processos na modalidade pregão, surge o personagem principal e foco deste estudo, o pregoeiro. Conforme prevê a legislação, no artigo $7{ }^{\circ}$ inciso II do Decreto $n^{\circ} 3.555 / 00$ (BRASIL, 2000b), cabe à autoridade competente de cada órgão público, designar o pregoeiro e a respectiva equipe de apoio que atuarão nos processos licitatórios. Nesse mesmo artigo do Decreto n 3.555/00 (BRASIL, 2000b), destaca-se a determinação legal que "Somente poderá atuar como pregoeiro o servidor que tenha realizado capacitação específica para exercer a atribuição".

Verifica-se daí a relevância do papel de pregoeiro e, particularmente, a necessidade de se fazer uma escolha adequada daquele que exercerá tal atividade na Instituição. Sobre esta realidade, Soares (2009, p.13) comenta:

\begin{abstract}
no pregão, a responsabilidade de conduzir e julgar é pessoal e exclusiva do pregoeiro, que atuará sozinho, ao contrário do que ocorre nas comissões de licitação e que, com isso, o pregoeiro não pode ser qualquer servidor, mas alguém que tenha determinadas características que lhe permita ter uma postura proativa de negociador dos interesses dos órgãos e entidades, ajustando com o fornecedor a contratação mais vantajosa, devendo ser cobrado para atuar dessa forma, já que é corresponsável pelos resultados do certame.
\end{abstract}

Em verdade, o gestor precisa contar com critérios que lhe auxiliem no processo de seleção do servidor que exercerá essa importante função. O pregoeiro deve não apenas reunir conhecimentos da legislação específica e geral, mas igualmente contar com habilidades que Ihe permitam conduzir, de forma efetiva, as negociações, estimulando a competição através dos lances verbais (pregão presencial) ou via Internet (pregão eletrônico). Momentos surgirão em que somente a capacidade conciliatória solucionará impasses e permitirá o prosseguimento do certame de forma satisfatória e positiva para a administração, pois a responsabilidade pelas decisões do pregoeiro é única e exclusivamente dele.

O servidor designado para tal função necessariamente dever reunir não só competências técnicas, mas também comportamentais.

Na visão de Rabaglio (2001, p. 4), "Todo profissional tem um perfil de competências que compreende competências técnicas e comportamentais". Com relação às competências técnicas, a autora define como todo conhecimento e habilidade no domínio de técnicas ou funções específicas, como exemplo, cita um técnico em contabilidade. Sobre competências comportamentais, a autora as define como as atitudes e comportamentos adequados as atribuições a serem desempenhadas, como exemplo, cita iniciativa, criatividade, liderança etc. 
Portanto, de acordo com o que foi exposto formula-se a seguinte pergunta de pesquisa: Como elaborar uma sistemática de seleção de pregoeiros por competências no IFSC, campus São José?

Para responder a essa questão, foi traçado como objetivo geral elaborar uma sistemática de seleção de pregoeiros por competências no IFSC, campus São José. Esse objetivo foi operacionalizado nos objetivos específicos de identificar as atribuições e competências necessárias ao desempenho da função de pregoeiro; descrever como ocorre o processo de seleção e designação dos servidores para desempenhar a função de pregoeiro no IFSC, campus São José; consolidar uma matriz de competências para a função de pregoeiros; e definir critérios e procedimentos para a designação.

\section{FUNDAMENTAÇÃO TEÓRICA}

Neste capítulo, são apresentados os fundamentos teóricos que possibilitaram um estudo mais detalhado dos temas escolhidos para este estudo.

\subsection{Gestão Universitária}

Concebe-se a universidade como uma instituição que tem como principal característica ser uma instituição social. Significa dizer que, para isso, deve estar comprometida com o desenvolvimento da sociedade onde está inserida, contribuindo para a formação de profissionais que possam estar a serviço de toda a população.

A universidade não pode perder de vista a necessidade de estar constantemente repensando a sua função social, para que possa refletir a própria sociedade onde atua. Sua função não é somente a formação de profissionais de nível superior, mas também a criação e disseminação de conhecimento, mantendo docentes atualizados e capacitados para efetuar a transmissão de conhecimento e contribuir para uma formação muito mais sólida do corpo discente, tornando-os profissionais capazes de contribuir para o desenvolvimento social nas mais diversas áreas do conhecimento humano e, assim, legitimar-se junto a esta sociedade.

Tendo em vista esta concepção de universidade, Silva Junior (2006, p. 54) faz as seguintes considerações sobre gestão universitária:

\footnotetext{
A gestão universitária é vista como a prática gerencial envolvendo aspectos como a estratégia e a estrutura organizacional, a dinâmica e o comportamento de pessoas e grupos de pessoas que atuam nas instituições universitárias, considerando que a análise dessa estratégia, estrutura e dinâmica organizacional focaliza fatores como missão, propósito global e objetivos, porte, sistemas hierárquicos, de controle e de comunicação, métodos e procedimentos em organizações universitárias, além da avaliação de desempenho institucional.
}

De acordo com Souza (2008), as universidades são vistas pelos estudiosos da área de gestão universitária, como organizações complexas, para quem as características organizacionais dessas instituições são muito diferentes de outras organizações, portanto considera que as teorias tradicionais da administração não se aplicam a elas.

Ao abordar o tema empreendedorismo na gestão universitária, Buarque (1992) dá a sua contribuição, ao afirmar que competência, sensibilidade política e capacidade intelectual, são atributos imprescindíveis para um gestor universitário poder lidar com crises internas e externas nessas instituições. Não pode faltar também, a capacidade para imaginar e criar o futuro, não devendo confundir a política com partidarismo ou corporativismo.

Segundo o autor, é de suma importância o empreendedorismo na gestão dessas instituições, para que possam melhor se adaptar às mudanças exigidas pela sociedade, e promover a melhoria no nível de qualidade de vida da população.

Quanto aos institutos federais, os mesmos possuem diversas características semelhantes e, em muitos casos, idênticas às universidades. A Lei no 11.892, de 29 de dezembro de 2008 (BRASIL, 2008), criou os Institutos Federais e instituiu no âmbito do sistema federal de ensino a rede federal de educação profissional, científica e tecnológica, vinculada ao Ministério da Educação (MEC).

Conforme estabelece o artigo $2^{\circ}$ dessa mesma Lei, os Institutos Federais são instituições de educação superior, básica e profissional, pluricurriculares e multicampi, especializados na oferta de educação profissional e tecnológica nas diferentes modalidades de ensino, com base na conjugação de conhecimentos técnicos e tecnológicos com as suas práticas pedagógicas (BRASIL, 2008, art. 2º.

No que diz respeito à estrutura organizacional, os Institutos Federais terão como órgão executivo a reitoria, composta por 1 (um) Reitor e 5 (cinco) Pró-Reitores (BRASIL, 2008, art. 11\%). Percebe-se, na edição desta Lei (BRASIL, 2008), que os Institutos Federais conquistaram status de universidade por apresentarem características dessas instituições.

\subsection{Competências}

Para Fleury e Fleury (2004, p. 30), competência pode ser definida como "um saber agir responsável e reconhecido, que implica mobilizar, integrar, transferir conhecimentos, recursos, habilidades, que agreguem valor econômico à organização e valor social ao indivíduo". 
Com esse mesmo entendimento, inclusive quanto à definição de competências técnicas e comportamentais, Rabaglio (2001, p. 3) define Competência como "um conjunto de conhecimentos, habilidades, atitudes e comportamentos que permitem ao indivíduo desempenhar com eficácia determinadas tarefas em qualquer situação".

Propondo uma definição que reúna diversas dimensões, e consequentemente reúna várias formulações, para Zarifian (2001, p. 68) "A competência é "o tomar iniciativa" e "o assumir responsabilidade" do indivíduo diante de situações profissionais com as quais se depara".

Dutra (2002) apresenta como contribuição para melhor entendimento do tema, a origem das principais correntes que deram origem ao termo. A primeira corrente teórica é formada por autores norte-americanos, tendo desenvolvido seus trabalhos nas décadas de 1970 e 1980. Para esses autores, "competência é o conjunto de qualificações (underlying characteristics) que permite que uma pessoa tenha performance superior em um trabalho ou situação" (DUTRA, 2002, p. 127). A segunda corrente teórica indicada por Dutra (2002) é a francesa, e surgiu nos anos 80 e 90 . Contestavam a definição de competência, associando-a as realizações das pessoas, ou seja, àquilo que proveem, produzem ou entregam.

De acordo com Durand (1998) competência significa o conjunto de conhecimentos, habilidades e atitudes interdependentes e necessárias ao alcance de determinado propósito.

Diante desse histórico, cabe definir a gestão por competências que segundo Leme (2008, p. 1), "é o processo de conduzir os colaboradores para atingirem as metas e os objetivos da organização por meio de suas competências técnicas e comportamentais". Na visão do autor, não é o processo de mapeamento em si, mas o que se faz com as competências mapeadas.

A gestão por competências oficialmente foi instituída no serviço público federal brasileiro com a publicação do Decreto no 5.707/2006 (BRASIL, 2006).

Conforme o mesmo Decreto sobre gestão por competências, entende-se "[...] gestão da capacitação orientada para o desenvolvimento do conjunto de conhecimentos, habilidades e atitudes necessárias ao desempenho das funções dos servidores, visando ao alcance dos objetivos da instituição" (BRASIL, 2006, art. 20, inciso II.).

Nesse entendimento, sobre os objetivos da implantação da gestão por competências, Rabaglio (2001, p. 8) esclarece:

O grande objetivo da Gestão por Competências é criar um modelo de competências para cada função dentro da empresa, isto é elaborar um mapeamento de competências que façam parte das estratégias de competitividade e diferenciação no mercado de trabalho.

Deste modo, um tema fundamental quando se trata da gestão por competências é a elaboração do mapeamento de competências, assim sendo, de acordo com Carbone et al. (2006, p. 172), o mapeamento tem como finalidade:

\footnotetext{
Identificar o gap ou lacuna de competências, ou seja, a discrepância entre as competências necessárias para concretizar a estratégia corporativa e as competências internas existentes na organização. [...] Para essa identificação, geralmente é realizada primeiro uma pesquisa documental, que inclui a análise do conteúdo da missão, da visão de futuro, dos objetivos institucionais e de outros documentos relativos à estratégia da organização.
}

Neste ponto, ou seja, sobre a etapa de mapeamento de competências, seguem os autores Pires et al. (2005) destacando que a organização deve primeiramente identificar e conhecer quais são os seus objetivos estratégicos e, após formular os seus planos estratégicos, paralelamente deve desencadear a etapa de mapeamento de competências, o que contribuirá para a implantação da gestão por competências.

Segundo Carvalho et al. (2009), a pesquisa documental, as entrevistas, o grupo focal e os questionários estruturados, são algumas das metodologias que podem ser utilizadas para o processo de mapeamento de competências.

Um dos processos possíveis tendo o mapeamento de competências finalizado é a seleção por competências. Segundo Leme (2008), para contratar novos colaboradores, a seleção por competências é a melhor metodologia, pois permite identificar características comportamentais no candidato, ou seja, suas competências comportamentais.

O autor ainda apresenta as seguintes considerações sobre o tema:

[...] Seleção por Competências tem o objetivo de apresentar não apenas tecnicamente, mas comportamentalmente, a possibilidade de ser identificado o melhor candidato para o cargo. Isso é economia. Quanto mais próximo do cargo, menores serão os investimentos em treinamentos básicos, canalizando os recursos para treinamentos com finalidade corretiva, além de uma série de outras vantagens (LEME, 2005, p. 120).

Segundo Brandão (2012) para selecionar por competências, as técnicas devem ser aplicadas objetivando medir conhecimentos, habilidades e atitudes. Para o autor, é possível também aplicar provas com questões objetivas, onde o candidato responderá aos questionamentos que simulem uma situação de trabalho, em que o mesmo irá expressar como agiria nesta situação. Espera-se com isso, registrar certas competências comportamentais com base em suas respostas.

O planejamento é a primeira etapa para o processo de aquisição de recursos humanos. Esse plano deve partir da visão estratégica da organização e seria composto pela definição do perfil, identificação dos caminhos para a busca 
ou fontes de recrutamento, prever avaliação de pré-seleção, entrevistas, avaliações e apresentação dos finalistas (ALLES, 2008).

\title{
2.3 Licitação e a função do pregoeiro
}

Toda a aquisição de bens e serviços por parte da Administração Pública Federal, Estadual ou Municipal, ocorre por força de um conjunto de leis que regem tal atividade. O servidor público que atua nesta área, ou seja, nas licitações públicas, precisa conhecer profundamente todas essas leis, para que possa atuar como digno representante da sociedade brasileira, que, por meio do pagamento de tributos, possibilita o funcionamento do Estado brasileiro. Para Meirelles (2002, p. 274), licitação é conceituada como:

Licitação é o procedimento administrativo mediante o qual a Administração pública seleciona a proposta mais
vantajosa para o contrato de seu interesse. Como procedimento desenvolve-se através de uma sucessão
ordenada de atos vinculados para a Administração e para os licitantes, o que propicia igual oportunidade a todos
os interessados e atua como fator de eficiência e moralidade nos negócios administrativos.

Corroborando com esse mesmo entendimento, Mello (2009, p. 517) conceitua a licitação como "um certame que as entidades governamentais devem promover e no qual abrem disputa entre os interessados e com elas travar determinadas relações de conteúdo patrimonial, para escolher a proposta mais vantajosa às conveniências públicas".

Sobre as modalidades licitatórias, o artigo $22^{\circ}$ da Lei 8.666/93 (BRASIL, 1993) estabelece as seguintes: concorrência, tomada de preços, convite, concurso e leilão.

Uma nova modalidade de licitação surgiu com o advento da Lei n 10.520, de 17 de junho de 2002 (BRASIL, 2002), denominada de Pregão. Por meio do Decreto n 3.555, de 08 de agosto de 2000 (BRASIL, 2000b) a modalidade pregão foi instituída na forma presencial e o Decreto n 5.450, de 31 de maio de 2005 (BRASIL, 2005) instituiu na forma eletrônica.

Para Santana (2006, p. 26), "o pregão é modalidade de licitação que se realiza presencial ou eletronicamente, na qual há disputa para se ofertar à Administração Pública o melhor preço entre os licitantes, verbalmente ou não, visando à contratação de bens e serviços comuns".

Segundo Boselli (2008, p. 30), ao falar do perfil da pessoa que irá exercer a função de pregoeiro ensina:

\begin{abstract}
Não basta a legislação apontar as atribuições do pregoeiro. Devido às características dessa nova função na Administração Pública, a pessoa que vai desempenhá-la precisa ter um perfil próprio, no qual podemos destacar as seguintes características como principais: conhecer bem o pregão, boa noção da legislação aplicável, agilidade, ter e demonstrar seriedade, capacidade de negociação, firmeza ao decidir, extrovertido para falar em público, educação, cortesia e tranquilidade.
\end{abstract}

As atribuições do pregoeiro estão previstas no artigo $9^{\circ}$ do Decreto no 3.555 (BRASIL, 2000b) quando atua no pregão realizado na forma presencial, por outro lado, no pregão realizado na forma eletrônica, as atribuições do pregoeiro estão previstas no Decreto n 5.450 (BRASIL, 2005), no seu art. 11º, podendo-se citar: coordenar o processo licitatório, receber, examinar e decidir as impugnações e consultas ao edital, apoiado pelo setor responsável pela sua elaboração, conduzir a sessão pública na internet entre outras.

\section{METODOLOGIA}

A pesquisa caracteriza-se como qualitativa e descritiva e visa justamente descrever o âmbito de atuação dos pregoeiros do IFSC, campus São José, em profundidade.

Com relação aos meios, foi utilizada a pesquisa documental que, segundo Almeida (2002, p. 65), é "a investigação documental é a realizada em documentos conservados no interior de órgãos públicos e privados de qualquer natureza, ou com pessoas".

Ainda quanto aos meios, têm-se a pesquisa de campo e participante. Para Severino (2007, p. 120), a pesquisa participante "é aquela em que o pesquisador, para realizar a observação dos fenômenos, compartilha a vivência dos sujeitos pesquisados, participando, de forma sistemática e permanente, ao longo do tempo da pesquisa, das suas atividades". A opção por esse tipo é decorrente do fato do pesquisador ser servidor e atuar na unidade de estudo indicada para a pesquisa.

Trata-se também de um estudo de caso, pois analisou os processos licitatórios em uma instituição real, no caso o IFSC, tendo como foco o campus São José, onde ocorre a participação do servidor no exercício da função de pregoeiro.

Com o intuito de atender ao objetivo proposto no presente artigo, como sujeitos da pesquisa foram selecionados três gestores ligados diretamente aos pregoeiros, os dois pregoeiros que estão na ativa e mais uma pregoeira que já atuou durante sete anos na função. Portanto foram seis, o total de sujeitos participantes da pesquisa. Tal escolha foi realizada de forma intencional, utilizando-se os critérios de acessibilidade e tipicidade, uma vez que este pesquisador exerce a função de pregoeiro no campus São José. 
Como instrumentos de coleta de dados foram utilizados a entrevista semiestruturada, com o uso de um roteiro de entrevista, aplicada junto aos gestores e pregoeiros e a observação participante.

Sendo esta pesquisa classificada como qualitativa, para a análise dos dados coletados por meio dos instrumentos selecionados, foi utilizado o método de análise de conteúdo.

\section{RESULTADOS DA PESQUISA}

Para o primeiro objetivo específico apresentado para este estudo, a análise das entrevistas realizadas com os gestores e pregoeiros, das informações obtidas com a aplicação da técnica observação participante, onde foi possível acompanhar os pregoeiros no seu dia a dia, ou seja, durante o desempenho das suas atribuições, e a pesquisa documental, onde documentos internos do (IFSC) sobre licitações foram consultados, propiciaram levantamento não só das atribuições legais, mas também das atividades desenvolvidas além das previstas em lei. Nesse sentido, segundo Carbonet et al. (2009), algumas técnicas de pesquisa são utilizadas para identificar competências entre elas destaca: entrevista, observação e análise documental, técnicas essas utilizadas nesse estudo.

Como atribuições legais os gestores e pregoeiros apontaram as seguintes: a) as previstas na legislação Lei 8.666/93, Lei 10.520/02 Decreto 3.555/00, Decreto 5.450/05 e Instrução Normativa № 01/09 (IFSC); b) Coordenação de todo o processo licitatório e a operacionalização do pregão. Como atividades desenvolvidas além das previstas em lei apontaram: a) Montagem do processo licitatório, não previsto na legislação, porém tal atividade foi incorporada pelos pregoeiros do campus São José; b) Coleta de orçamentos para compor os preços estimados dos processos licitatórios, e também sem previsão legal, porém tal atividade foi incorporada pelos pregoeiros do campus São José e c) Montagem de processos licitatórios nas seguintes modalidades: tomada de preços, concorrência, convite. Também das dispensas de licitação e inexigibilidade de licitação.

Com relação ao mapeamento das competências necessárias para a função de pregoeiro, a análise realizada, possibilitou também, o levantamento dos indicadores de competências traduzidos em conhecimentos, citando como exemplos: conhecimento da legislação aplicada às licitações, dos procedimentos para operacionalização do pregão, conhecimentos da área administrativa entre outros. Habilidades, citando como exemplos: saber usar os sistemas para execução das licitações e principalmente a modalidade pregão, habilidade para saber trabalhar em equipe, para saber conduzir as reuniões e a própria sessão de pregão entre outros. Atitudes necessárias ao desempenho da função de pregoeiro, citando como exemplos: assumir postura de transparência na condução do processo, agir com tranquilidade para tomar decisões, assumir postura de responsabilidade com a Instituição, os recursos e o patrimônio público entre outros.

Os entrevistados apontaram as facilidades e dificuldades encontradas no exercício da função e como exemplo têm-se como facilidades: oportunidade de trabalhar com pessoas experientes, equipamentos adequados e ambiente de trabalho agradável entre outros. Como dificuldades têm-se: centralização de processos licitatórios para serviços terceirizados na Reitoria e obtenção de orçamentos para compor os preços de referência dos processos entre outros.

Uma vez apresentados os indicadores de competências traduzidos em conhecimentos, habilidades e atitudes (CHA), é possível perceber indicativos de competências à medida que se juntam esses indicadores por similaridade e complementaridade. Procedendo dessa forma, foram identificadas as seguintes competências: legal, de liderança, de comunicação, de negociação, administrativa, emocional e de operação do pregão e demais sistemas.

As competências foram identificadas em conjunto com os sujeitos da pesquisa, ou seja, gestores e pregoeiros que validaram todos os grupos de competências citados.

Com relação ao segundo objetivo proposto para este estudo, como resultados alcançados constatou-se que não existe um processo de seleção e designação dos servidores para desempenhar a função de pregoeiro no campus São José. A Escolha fica sob a responsabilidade do chefe do Departamento de Administração, ou Diretor Geral do campus, ou ambos, sem nenhum critério.

Cabe destacar que por não haver um processo de seleção formalizado e institucionalizado, como ficou comprovado junto aos gestores ligados diretamente ao pregoeiro, não existe no Plano de Desenvolvimento Institucional (PDI), Regimento Geral ou Estatuto do IFSC e muito menos no Regimento Interno do campus São José, qualquer referência sobre o tema. Todos os documentos internos da área de licitações pesquisados não tratam do processo de escolha do pregoeiro, apenas das suas atribuições e da legislação aplicável.

Com relação ao terceiro objetivo específico estabelecido para esta pesquisa, ou seja, consolidar uma matriz de competências para a função de pregoeiros, com base nas competências identificadas e elencadas anteriormente, foi possível elaborar uma matriz de competências que juntasse todos os indicadores apontados pelos entrevistados e alguns desses indicadores foram citados como exemplos anteriormente.

A matriz de competências identificada está resumida no quadro 1, a seguir: 
Quadro 1 - Competências necessárias para a função de pregoeiro

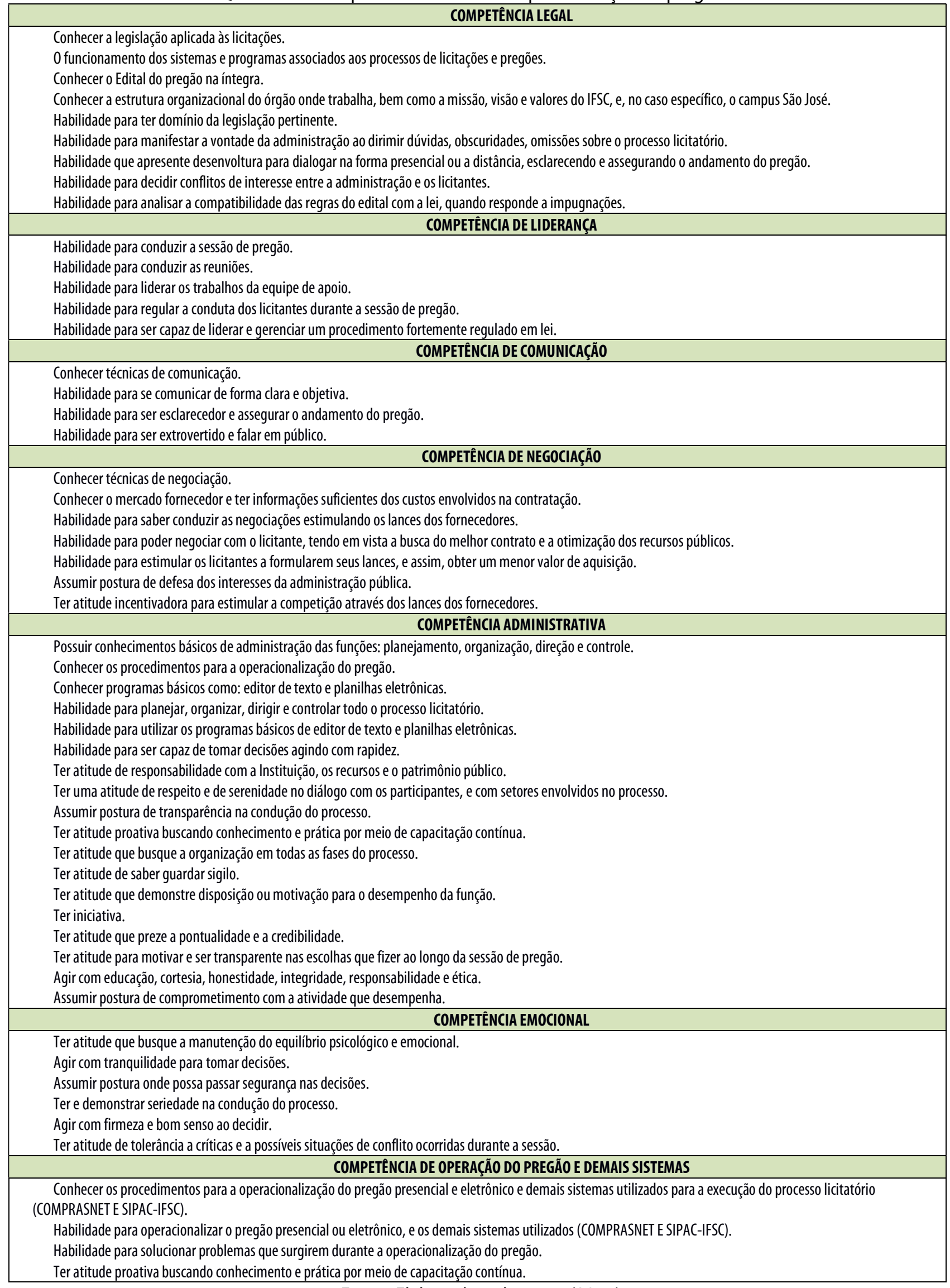

Fonte: Elaborado pelo autor (2017).

Cardoso (2006) por sua vez, destaca que esses mapas ajudam a detectar e avaliar conhecimentos, habilidades e atitudes necessárias para a realização das atividades. Possibilitam à organização identificar de forma clara as lacunas de deficiência em seu quadro funcional.

Para o quarto e último objetivo específico estabelecido, definir critérios e procedimentos para a designação, a aplicação da entrevista semiestruturada junto aos gestores e pregoeiros, propiciou a obtenção de sugestões sobre 
critérios e procedimentos, a serem aplicados quando da realização do processo de seleção de servidores para a função.

Por sua vez, na literatura especializada citada no capítulo 2 Fundamentação teórica, os autores não fazem referência quanto a critérios e procedimentos para a escolha do pregoeiro e se limitam a abordar o perfil do candidato ideal. Quanto à legislação, não apresenta critérios e procedimentos para o processo de seleção, porém, determina o responsável pela designação para a função.

Como resultado, gestores e pregoeiros apresentaram sugestões de critérios e procedimentos para o processo seletivo, sendo os principais critérios sugeridos: a) ser graduado preferencialmente em administração, depois ciências contábeis, economia ou direito, b) que o candidato possua experiência prática como pregoeiro, possua curso de formação de pregoeiros ou tenha atuado na área de licitações, c) que o candidato possua experiência em práticas administrativas e d) que saiba trabalhar com planilhas eletrônicas e sistemas informatizados. Principais procedimentos: a) quem detecta a necessidade de pessoal para atuar na função, são os próprios pregoeiros que estão na ativa, b) levam ao conhecimento da chefia imediata tal necessidade. Se houver consenso sobre a necessidade, o assunto é levado ao Diretor administrativo que concordando, informa ao diretor do campus a necessidade com as devidas justificativas e c) caso o Diretor do campus concorde com a solicitação, autoriza o início do processo para a seleção do candidato, de acordo com os critérios e procedimentos estabelecidos.

\subsection{Elaboração de uma sistemática de seleção de pregoeiros por competências, no IFSC, campus São José}

Nesta seção, apresenta-se como contribuição, a elaboração de uma sistemática de seleção de candidatos ao exercício da função de pregoeiro, com base no estudo realizado.

\subsubsection{Planejamento do processo de seleção}

Propõe-se que esta etapa seja assim composta: definição do perfil de competências (PC) para a função de pregoeiro, fontes de recrutamento, pré-seleção, entrevistas, avaliações e resultado final.

Sobre o planejamento da seleção, Alles (2008, tradução nossa) ressalta que é a primeira etapa para o processo de "aquisição" de recursos humanos. Deve partir da visão estratégica da organização e seria composto pela definição do perfil, identificação dos caminhos para a busca ou fontes de recrutamento, prever avaliação de pré-seleção, entrevistas, avaliações e apresentação dos finalistas.

Como sugestão, deverá ser formada uma comissão que terá como competências, coordenar todo o processo de seleção que envolve: a aplicação dos instrumentos de coleta de dados previstos no planejamento, aplicação da avaliação prevista, proceder a análise dos dados obtidos e a apresentação do candidato selecionado. Essa comissão terá como integrantes um representante da área de gestão de pessoas, os pregoeiros que atuam no campus, e um gestor ligado diretamente aos pregoeiros, neste caso, o chefe da área onde atuam os pregoeiros em razão da proximidade aos mesmos.

Com relação ao primeiro tópico, "definição do perfil de competência (PC)", quando foram definidos os sete grupos de competências necessárias para a função de pregoeiro, ou seja, as competências: legal, de liderança, de comunicação, de negociação, administrativa, emocional e de operação do pregão e demais sistemas, definiu-se o perfil de competências (PC) ideal do servidor para ocupar a função. Nesse sentido, segundo Rabaglio (2001, p. 5), “[...] quando definimos as competências para um determinado cargo, estamos descrevendo todas as características técnicas e comportamentais que o profissional precisa ter para realizar com sucesso todas as suas atribuições".

Quanto ao segundo tópico "fontes de recrutamento", quando aborda as fontes de recrutamento destaca as fontes de referência interna, como exemplo cita as indicações feitas por funcionários da própria empresa, solicitações espontâneas, ou seja, um possível candidato manifesta interesse pela vaga ou vagas em aberto e por último a própria base de dados da empresa. A fonte de referência interna, segundo a autora, tem como vantagens o fator econômico, agilidade, segurança quanto aos resultados, funciona como motivação para os colaboradores e retorno de investimento em formação (ALLES, 2008, tradução nossa).

Sobre as fontes de referência externa, Alles (2008, tradução nossa) apresenta como exemplos a internet, instituições de ensino, associações profissionais, consultorias e eventos específicos.

Os pregoeiros quando entrevistados sugeriram como um dos procedimentos para o processo de seleção, que o recrutamento inicialmente deva ser interno, ou seja, possa ser feito em outros setores, onde qualquer servidor poderá manifestar interesse, porém, existe outra possibilidade importante, que é a remoção que ocorre frequentemente no IFSC por meio de Edital de remoção, ou seja, o chamado "Processo Seletivo para a Remoção a Pedido". "A Remoção a pedido, é o deslocamento do servidor, no âmbito do mesmo quadro, com ou sem mudança de sede e dar-se-á sempre mediante contrapartida de vaga" (IFSC, Edital n 60/2016/DGP). Portanto, como proposta para o recrutamento interno, apresenta-se duas fontes possíveis: o recrutamento em outros setores, e por meio do processo de remoção junto a outros campi do próprio IFSC.

Assim sendo, caso não seja possível recrutar e selecionar um servidor por meio do recrutamento interno, e caso exista concurso público vigente e candidatos aprovados, a Direção do campus São José poderá solicitar à Reitoria do IFSC a convocação de candidatos aprovados principalmente para o cargo de administrador, pois com isso atenderia 
o critério da formação apresentado por gestores e pregoeiros. Também podem ser convocados candidatos aprovados para o cargo de assistente em administração, que possuam graduação em administração.

Não havendo a possibilidade de recrutar um servidor para a função de pregoeiro pelas duas formas apresentadas, recrutamento interno ou externo, caberá ao Diretor do campus, decidir se poderá aguardar até que uma das possibilidades apareça, ou se indica um servidor que assumirá a função temporariamente.

Sobre o terceiro tópico "pré-seleção", esta fase contém as seguintes etapas: triagem 1 para coleta das informações básicas necessárias sobre o candidato (idade, estudo entre outros, e aspectos funcionais como a experiência) e triagem 2, onde se propõe aplicar um questionário de pré-entrevista a ser enviado por e-mail. Cabe observar que todos os candidatos participarão das triagens 1 e 2 e que após serem avaliados, os aprovados irão para a próxima etapa, denominada entrevistas com foco em competências.

Os questionários on-line, segundo Carvalho (2009), tornaram-se um recurso cada vez mais utilizado pela facilidade de acesso e baixo custo para aplicação. Podem ser utilizados em entrevistas individuais ou coletivas, telefônicas, enviados por correio ou de forma eletrônica, ou seja, e-mail.

Assim sendo, dando continuidade ao processo, nessa etapa devem ser considerados também, os critérios por ordem de importância, sugeridos pelos gestores e pregoeiros. Sugere-se nessa fase que se aplique a ponderação para cada critério considerado. Como temos seis critérios, o critério de maior importância recebeu peso 6, e no mesmo sentido, o critério com menor importância recebeu peso 1 nessa fase de ponderação, de forma que a ponderação se manteve contínua e linear entre cada critério.

A nota a ser atribuída a cada candidato, em cada critério, será a proposta por Rabaglio (2001) a seguir apresentada:

$$
\begin{aligned}
& 4 \text { = acima da competência esperada; } \\
& 3 \text { = aprovado; } \\
& 2 \text { = favorável; } \\
& 1=\text { favorável com restrições } \\
& 0=\text { não recomendado. }
\end{aligned}
$$
fases.

A pré-seleção, portanto, determina a continuidade ou não do candidato no processo de seleção para as próximas

Recebidos os questionários preenchidos dos interessados, a etapa seguinte será obter a nota do candidato nessa etapa (TRIAGEM 2), aplicando-se a fórmula 1:

\section{(Fórmula 1)}

$$
\text { Desempenho }=\frac{\text { Nota critério } 1 \times \text { Peso critério } 1+(\ldots)+\text { Nota critério } 9 \times \text { Peso critério } 9}{\sum \text { Pesodetodososcritérios }}
$$

Será aprovado o candidato que obtiver o desempenho mínimo "2".

Caso ocorra empate, os candidatos nessa condição estarão aprovados automaticamente para a próxima fase, qual seja a entrevista comportamental, com foco em competências. Caso o candidato ou candidatos não alcancem o desempenho mínimo exigido, caberá ao Diretor Geral do campus proceder à indicação para posterior homologação da Reitora do IFSC. Nesse caso, não serão realizadas as próximas etapas, e consequentemente o processo estará encerrado.

No quarto tópico "entrevistas com foco em competências", a entrevista comportamental segundo Rabaglio (2001) é utilizada para investigar o comportamento passado de uma pessoa, em uma situação semelhante da competência que se deseja investigar. Como diferenciais apresenta além da investigação do comportamento passado, ser planejada com base no perfil de competências e personalizada para cada PC. Os tipos de perguntas usadas são abertos, específicas e com o verbo de ação no passado. Visam obter respostas que contenham contexto ação e resultado (RABAGLIO, 2001).

Com base nas seguintes competências básicas para a função de pregoeiro: legal, de liderança, de comunicação, de negociação, administrativa, emocional e de operação do pregão e demais sistemas, identificadas ao longo desse estudo, foram elaboradas perguntas a serem formuladas aos candidatos no momento da entrevista.

Citam-se como exemplos as seguintes perguntas que podem ser formuladas: a) quanto à competência legal "Já ocorreu com você alguma situação onde precisou se inteirar de uma determinada legislação e assim ter segurança para encaminhar uma solução viável para um caso específico? Fale a respeito". Com esse questionamento objetivase observar no seu comportamento, quais recursos e formas utilizadas para obter conhecimentos necessários sobre a legislação.

Outro exemplo, agora quanto à competência de "comunicação": b) "Relate um acontecimento onde você precisou falar em público". Comportamento a ser observado é quanto à facilidade ou dificuldade para falar em público. Entre outros questionamentos que podem ser feitos no momento da entrevista com foco em competências.

Sobre a pontuação para o nível de competências, nessa etapa deve-se indicar o nível de competências encontradas no candidato durante a realização da entrevista. Para isso propõe-se novamente atribuir a seguinte pontuação, utilizando-se os critérios e a pontuação sugeridos por Rabaglio (2001):

$$
\begin{aligned}
& 4 \text { = acima da competência esperada; } \\
& 3 \text { = aprovado; } \\
& \text { 2= favorável; }
\end{aligned}
$$


$1=$ favorável com restrições

$0=$ não recomendado.

Caso nessa etapa nenhum candidato alcance a nota mínima exigida, ou seja, "2 - favorável", o Diretor Geral do campus indicará um dos candidatos participantes do processo e finaliza nesse ponto o processo seletivo. Caso contrário, existindo candidato ou candidatos aprovados, passarão para a próxima fase de capacitação e ambientação.

\subsubsection{Capacitação e ambientação}

O candidato aprovado por certo não reunirá todos os conhecimentos, habilidades e atitudes necessárias para o exercício da função de pregoeiro, portanto, quando da sua capacitação e ambientação, além da constatação do nível de competências encontradas no candidato a ser avaliado, será constatada também a necessidade de treinamentos visando sua melhor adequação ao cargo.

Na prática, nessa etapa deverão ser aplicados os seguintes procedimentos:

1) o candidato ou candidatos aprovados nas etapas anteriores deverão participar da montagem e a operacionalização de pelo menos três processos licitatórios. A comissão formada pelos pregoeiros, o gestor e o representante da área de gestão de pessoas, fará a avaliação do desempenho de cada candidato, buscando identificar e anotar as competências demonstradas;

2) será atribuída a pontuação do item 4.1.1.5, para o nível de competência encontrada em cada candidato;

3) ao final dessa etapa, tem-se uma avaliação do candidato, a partir do nível de competências encontradas.

4) Caso nessa etapa nenhum candidato alcance a nota mínima exigida, ou seja, "2 - favorável", o Diretor Geral do campus indicará um dos candidatos participantes do processo e finaliza nesse ponto o processo seletivo.

Como último tópico tem-se a avaliação e resultado final. Esta é a última etapa do processo de seleção, onde serão apresentados ao setor requisitante e gestores os resultados das avaliações aplicadas nas etapas de pré-seleção, entrevistas com foco em competências e capacitação e ambientação. O resultado por sua vez é a apresentação do candidato que melhor pontuação recebeu em todas as etapas do processo e, portanto, possui o perfil mais adequado para o exercício da função de pregoeiro.

\section{CONCLUSÃO}

O Decreto Federal n 5707, de 23 de fevereiro de 2006 (BRASIL, 2006), instituiu a Política e as Diretrizes para o Desenvolvimento de Pessoal da administração pública federal direta, autárquica e fundacional. Estabelece como uma de suas finalidades conforme o inciso I do Art. 10 "melhoria da eficiência, eficácia e qualidade dos serviços públicos prestados ao cidadão" (BRASIL, 2006). Portanto, a determinação legal foi um dos fatores de grande importância que justificou a realização deste estudo.

Dessa forma, ao desenvolver tal atividade, que é particularmente importante para a administração de Instituições Federais de Ensino Superior (IFES), diante da cobrança cada vez maior da sociedade para que atuem com eficiência e responsabilidade na gestão dos recursos públicos, é que este pesquisador percebeu que o campus São José (IFSC) não conta com nenhum instrumento de apoio para a escolha dos candidatos a pregoeiro, nem tampouco estão formalmente definidas as competências exigidas para o exercício da função.

A metodologia aplicada viabilizou a definição das competências necessárias ao servidor para o desempenho da função de pregoeiro, e uma vez definidas as competências foi possível propor ações no sentido do aprimoramento do processo de seleção.

Para os gestores do IFSC, campus São José, essa pesquisa poderá contribuir para que conheçam qual perfil profissional é mais indicado, ou seja, quais os conhecimentos, habilidades e atitudes deve possuir o servidor, além das atribuições inerentes a função. Assim, poderão estabelecer critérios mais adequados, quando da realização do processo de seleção.

Esse estudo poderá beneficiar o setor responsável pelas licitações, tendo em vista que o gestor poderá fazer a indicação com base em critérios adequados, contribuindo para que os serviços não sofram solução de continuidade, e ao mesmo tempo, promovendo a eficiência e a eficácia dos trabalhos realizados.

Para outros campido IFSC, os resultados dessa pesquisa poderão ser aplicados, uma vez que todos os processos licitatórios seguem diretrizes idênticas estabelecidas pela Reitoria do IFSC, mas, sempre que possível, respeitando as peculiaridades inerentes a cada unidade.

Outro motivo relevante é a possibilidade de que outros órgãos possam utilizar os resultados obtidos, caso entendam conveniente, quando realizarem a seleção dos servidores para exercerem a função de pregoeiro. 


\section{REFERÊNCIAS}

ALLES, Martha Alicia. Selección por competências. Buenos Aires: Granica, 2008.

ALMEIDA, M. A. C. de. Projeto de pesquisa: guia prático para monografia. Rio de Janeiro: WAK, 2002.

BRASIL. Lei no 8.666, de 21 de junho de 1993. [1993]. Regulamenta o art. 37, inciso XXI, da Constituição Federal, institui normas e contratos da Administração Pública e dá outras providências. Disponível em: <http://www.planalto.gov.br/ccivil_03/Leis/L8666cons.htm>. Acesso em: 10 abr. 2016.

BRASIL. Medida Provisória n 2026, de 4 de maio de 2000. [2000a]. Institui, no âmbito da União, nos termos do art. 37, inciso XXI, da Constituição Federal, modalidade de licitação denominada pregão, para aquisição de bens e serviços comuns, e dá outras providências. Disponível em:

<http://www.planalto.gov.br/ccivil_03/mpv/Antigas/2026.htm>. Acesso em: 10 abr. 2016.

BRASIL. Decreto n 3.555, de 8 de agosto de 2000. [2000b]. Aprova o Regulamento para a modalidade de licitação denominada pregão, para aquisição de bens e serviços comuns. Disponível em: <HTTP//www.planalto.gov.br>. Acesso em: 10 abr. 2016.

BRASIL. Lei no 10.520, de 17 de junho de 2002. [2002]. Institui, no âmbito da União, Estados Distrito Federal e Municípios, nos termos do art. 37, inciso XXI, da Constituição Federal, modalidade de licitação denominada pregão, para aquisição de bens e serviços comuns, e dá outras providências. Disponível em: <http//www.planalto.gov.br>. Acesso em: 10 abr. 2016.

BRASIL. Decreto no 5450, de 31 de maio de 2005. [2005]. Regulamenta o pregão, na forma eletrônica, para aquisição de bens e serviços comuns, e dá outras providências. Disponível em: <http/www.planalto.gov.br $>$. Acesso em: 10 abr. 2016.

BRASIL. Decreto Federal n 5707, de 23 de fevereiro de 2006. [2006]. Institui a Política e as Diretrizes para o Desenvolvimento de Pessoal da administração pública federal direta, autárquica e fundacional, e regulamenta dispositivos da Lei no 8.112, de 11 de dezembro de 1990. Disponível em:

<http://www.planalto.gov.br/ccivil_03/_Ato2004-2006/2006/Decreto/D5707.htm>. Acesso em: 09 mar. 2016.

BRASIL. Lei no 11.892, de 29 de dezembro de 2008. [2008]. Institui a Rede Federal de Educação Profissional, Científica e Tecnológica, cria os Institutos Federais de Educação, Ciência e Tecnologia, e dá outras providências. Disponível em: <http://www.planalto.gov.br/ccivil_03/_ato2007-2010/2008/lei//11892.htm>. Acesso em: 10 abr. 2016.

BRANDÃO, H. P. Mapeamento de Competências: métodos, técnicas e aplicações em gestão de pessoas. São Paulo: Atlas, 2012.

BOSELLI, Paulo. Apostila capacitação e formação de pregoeiros, sistema de registro de preços- SRP, atualização da LC 123/06, incluindo o novo Decreto 6.204/07. São Paulo: Negócios Públicos, 2008.

BUARQUE, Cristóvam. Pequeno dicionário da crise universitária. Florianópolis: UFSC, 1992.

CARBONE, Pedro Paulo et al. Gestão por competências e gestão do Conhecimento. 2. ed. Rio de Janeiro: FGV, 2006.

CARVALHO, Antônio Ivo de et al. Escolas de governo e gestão por competências: mesa redonda de pesquisaação. Brasília, DF: ENAP, 2009. Disponível em:

<http://repositorio.enap.gov.br/bitstream/handle/1/398/livro_mesa_redonda.pdf?sequence=1\&isAllowed=y >. Acesso em: 06 abr. 2016.

CARDOSO, Gilson da Silva. Mapeamento das competências Funcionais: Estudo de caso em uma empresa de celulose e papel Ponta Grossa, Novembro - 2006. Dissertação apresentada como requisito parcial à obtenção do título de Mestre em Engenharia de Produção, do Programa de Pós-Graduação em Engenharia de Produção, Área de Concentração: Gestão Industrial, do Departamento de Pesquisa e Pós-Graduação, do Campus Ponta Grossa, da UTFPR. Disponível em:

<http://www.pg.utfpr.edu.br/dirppg/ppgep/dissertacoes/arquivos/40/Dissertacao.pdf>.Acesso em: 15 jul. 2016. 
DUTRA, Joel Souza. Gestão de Pessoas: Modelo, processos, tendências e perspectivas. São Paulo: Atlas, 2002. DURAND, T. Forms of Incompetence. Proceedings Fourth International Conference on Competence -Based Management. Oslo: Norwegian School of Management, 1998.

FLEURY, Afonso; FLEURY, Maria Teresa Leme. Estratégias empresariais e formação de competências: um quebra cabeça caleidoscópio da indústria brasileira. São Paulo: Atlas, 2004.

LEME, Rogerio. Aplicação prática de gestão de pessoas por competências: mapeamento, treinamento, seleção, avaliação e mensuração de resultados de treinamento. 2. ed. Rio de Janeiro: Qualitymark, 2008.

MEIRELLES, Hely Lopes. Licitação e contrato administrativo. 13. ed. São Paulo: Malheiros, 2002.

MELLO, Celso Antônio Bandeira de. Curso de direito administrativo.26. ed. São Paulo: Malheiros, 2009.

PIRES, Alexandre Kalil et al. Gestão por competências em organizações de governo. Brasília: ENAP, 2005. Disponível em: <http://www.enap.gov.br/documents/52930/585077/livro_gestao_competencias.pdf/cd493b19485e-42b1-bc0e-27578a89faea>. Acesso em: 06 abr. 2016.

RABAGLIO, Maria Odete. Seleção por competências. São Paulo: Educator, 2001.

SANTANA, Jair Eduardo. Pregão presencial e eletrônico: manual de implantação, operacionalização e controle. Belo Horizonte: Fórum, 2006.

SEVERINO, Joaquim Antônio. Metodologia do Trabalho Científico. São Paulo: Cortez, 2007.

SILVA JUNIOR, Annor da. Trajetória de crescimento, governança corporativa e gestão universitária: estudo de caso em três instituições de educação superior do tipo familiar. 2006. Tese (Doutorado) - Universidade Federal de Minas Gerais, Belo Horizonte. Disponível em:

<http://www.fucape.br/_public/producao_cientifica/6/TESE\%20ANNOR.pdf>. Acesso em: 23 abr. 2016.

SOARES, Maria Elisete. Licitações na modalidade pregão. 2009. 59f. Monografia (Especialização em Administração) - Fundação Getúlio Vargas, Belo Horizonte, 2009. Disponível em:

<http://www.der.mg.gov.br/images/TrabalhosAcademicos/maria_elisete_soares.pdf>. Acesso em: 23 maio 2016.

SOUZA, Irineu Manoel de. Empreendedorismo na gestão universitária. [2008]. Disponível em:<https://repositorio.ufsc.br/xmlui/bitstream/handle/123456789/61475/Empreendedorismo\%20na\%20Gest \%C3\%A30\%20Universit\%C3\%A1ria. pdf?sequence=1 >. Acesso em: 23 abr. 2016.

ZARIFIAN, Philippe. Objetivo competências: por uma nova lógica. Tradução de Maria Helena C. V. Trylinski. São Paulo: Atlas, 2001. 